\title{
Actinomycetes FROM HOSPITAL DUMP SOIL PRODUCE HIGHLY ACTIVE ANTIBIOTIC
}

\author{
SHOUVIK SAHA ${ }^{1,2}$, PRANAB ROY ${ }^{1}$ AND SUTANU SAMANTA2*
}

1Department of Biotechnology, Burdwan University, Rajbati, Bardhaman-713104, West Bengal, India.

2School of Biotechnology and Biosciences, Lovely Professional University, Phagwara-144411, Punjab, India.

*Corresponding Author: Email- sutanusamanta@gmail.com

Received: June 23, 2012; Accepted: July 18, 2012

\begin{abstract}
Antibiotic producing actinomycetes can be identified from soil from different locations including various geographical locations. But antibiotic producing actinomycetes are yet to be identified from hospital wasteland soil or drainage soil. In this study, we have identified 11 actinomycetes isolate from five different hospital wasteland and drainage soil of West Bengal, India. Only 1 isolate out of 11 isolates is found to be antibiotic producer and this antibiotic is showing high level of antibacterial activity against both gram positive and gram negative microorganisms. The crude extract of the antibiotic is found to be more active against gram positive microorganisms whereas ethyl acetate fractionated antibiotics is showing almost two fold more activity than its crude counterpart against gram negative microorganisms. Ethyl acetate fractionated antibiotic is demonstrating more activies than standard antibiotic, chloramphenicol against all the test microorganisms. MIC of the antibiotic is estimated to be $18 \mu \mathrm{g}$ against Bacillus cereus. Ethyl acetate fractionated antibiotic shows a single band on TLC plate.

Key words- Actinomycetes, Zone of inhibition, antimicrobial activity, wasteland soil, drainage soil.
\end{abstract}

Citation: Shouvik Saha, Pranab Roy and Sutanu Samanta (2012) Actinomycetes from Hospital Dump Soil Produce Highly Active Antibiotic. International Journal of Microbiology Research, ISSN: 0975-5276 \& E-ISSN: 0975-9174, Volume 4, Issue 6, pp.-258-262.

Copyright: Copyright@2012 Shouvik Saha, Pranab Roy and Sutanu Samanta. This is an open-access article distributed under the terms of the Creative Commons Attribution License, which permits unrestricted use, distribution and reproduction in any medium, provided the original author and source are credited.

\section{Introduction}

Actinomycetes comprise an extensive and diverse group of Grampositive, aerobic, mycelial bacteria and play an important ecological role in soil cycle as they primarily inhabit the soil [1]. Actinomycetes have characteristic biological aspects such as mycelial forms of growth that accumulates in sporulation and the ability to form a wide variety of secondary metabolites including most of the antibiotics. They have provided many important bioactive compounds of high commercial value and continue to be routinely screened for new bioactive compounds. These searches have been remarkably successful and approximately two thirds of naturally occurring antibiotics, including many of medical importance, have been isolated from Actinomycetes [2]. Almost $80 \%$ of the world's antibiotics are known to come from actinomycetes, mostly from the genera Streptomyces and Micromonospora [3]. It produces several antibiotics including of amino glycosides, anthracyclins, glycopeptides, b-lactams, macrolides, nucleosides, peptides, polyenes, polyethers and tetracycline [4].

According to the World Health Organization, over-usage and the improper and indiscriminate uses of antibiotics have led to the creation of antibiotic resistance in many bacterial pathogens. Nowadays, the drug resistant strains of pathogen emerge more quickly than the rate of discovery of new drugs and antibiotics. Rising numbers of antibiotic unresponsive infectious disease agents confront patients worldwide [5-6] and consensus has emerged that it is essential that novel antibiotic classes be developed as part of the strategy to control the emerging drug-resistant pathogens [7-9]. Therefore, there is a renewed interest in discovering novel classes of antibiotics that have different mechanisms of action [10-11]. The resistance problem necessitates the discovery of new antibacterial agents effective against pathogenic bacteria resistant to current antibiotics. Therefore, we need to isolate 
and screen more and more actinomycetes from different sources in hope of finding new actinomycetes strains that can produce antibiotics that have not been discovered yet and active against drug resistant pathogens.

The majority of actinomycetes are free living, saprophytic bacteria found widely distributed in soil, water and colonizing plants. Actinomycetes population has been identified as one of the major group of soil population [12], which may vary with the soil type. Hospital dump soil may be a wonderful source for isolation of new strain of actinomycetes which can produce new type of antibiotics which can kill pathogenic microorganisms which have developed resistance to existing antibiotics.

The present study is aimed at isolating actinomycetes from the soil samples of hospital dumping zones (rich in microbial population with high competition of survival) and hospital drainage soil and ascertains their anti-bacterial properties.

\section{Materials and methods Collection and Preparation of Soil Sample}

Hospital waste samples with soil had been collected from different hospital wasteland and drainage in plastic pouches, sealed and transferred to Biotechnology Research Laboratory of Department of Biotechnology of The University of Burdwan. The soil samples were dried for 3-4 days at room temperature. Then $1 \mathrm{gm}$ of each soil samples were added to a test tube containing $10 \mathrm{ml}$ of sterile water and serial diluted upto $10^{-4}$ under Laminar-Air flow Hood.

\section{Isolation of Actinomycetes:}

Starch-Casein Agar, Muller Hinton agar, Tryptic soy agar and Yeast mannitol agar were used for the primary screening of antibiotic-producing microorganisms. Rifampicin $(2.5 \mathrm{mg} / \mathrm{ml})$ and Amphotericin $B(50 \mathrm{mg} / \mathrm{ml})$ were added to inhibit bacterial and fungal contamination, respectively. Luria broth, Starch-Casein broth [13] and Nutrient agar were used to culture the test microorganisms for testing the antimicrobial property of isolated antibiotic-producers and screening of antibacterial activity by agar diffusion assay.

Serial diluted samples were spread on these media and incubated at $37^{\circ} \mathrm{C}$ for $70-72$ hours. After incubation, bacterial culture in $0.5 \%$ agar was spread over these colonies and incubated for 24 hours at $37^{\circ} \mathrm{C}$. Zones of inhibition (ZOI) were identified on these plates and the inhibitory capabilities of putative antibiotic-producing microbes were confirmed.

\section{Morphological Characterization}

The potent isolates were characterized by macroscopic characterization in which structure, colour, shape and appearance of colony of putative antibiotic-producing microorganisms were compared with Bergey's manual of Determinative Bacteriology, $9^{\text {th }}$ edition (2000) [14] and these microorganisms were identified.

Smear of the selected isolate was prepared on a clean glass slide followed by air dry and heat fixation. Head fixed smear was flooded with crystal violet and left for 1 minute. After that, it was washed with water and flooded with mordant Gram's iodine. Smear was decolorized with $95 \%$ ethyl alcohol and again washed with water and counter stained with safranin for 45 seconds and washed with water, dried with tissue paper and examined under $45 X$.

\section{Antibiotic Production}

The putative antibiotic-producing Actinomycetes were cultured in a shaker incubator at $37^{\circ} \mathrm{C}$ for 48 hours in $100 \mathrm{ml}$ conical flasks containing $50 \mathrm{ml}$ of Starch-Casein broth containing required essential components in optimized concentration [13].

These putative antibiotic-producing Actinomycetes cultures were centrifuged at $12,000 \mathrm{rpm}$ for 13 minutes and the supernatants were collected for the determination of antibacterial activity against the standard test organisms. Antibiotic compound was purified from the supernatants by solvent extraction method.

\section{Examination of Anti-Microbial Activity of the Antibiotic}

The test microorganisms used for determining antimicrobial activity in present study were the Gram-positive bacteria Bacillus cereus (MTCC 8159), Staphylococcus aureus (MTCC 737) and the Gram-negative bacteria Escherichia coli (MTCC 40), Pseudomonas aeroginosa (MTCC 4673).

Antibacterial activities of the isolated microorganism were measured by the development of zone of inhibition in Agar diffusion assay in which sterile Starch-Casein agar plates were prepared and test micro-organisms were spread on different plates and allowed to become dry by keeping them at room temperature in sterile condition for 30 minutes. After drying, three wells were made in every plate by puncher and $100 \mu$ l of supernatant solution of antibiotic preparation was poured into one well of every plate. The other wells were filled with sterile broth and standard antibiotic solution (Chloramphenical $0.4 \mathrm{mg} / \mathrm{ml}$ ) and incubated for 48 hours at $37^{\circ} \mathrm{C}$. The Zone of inhibition was assessed by determining its diameter.

The Minimum inhibitory concentration (MIC) was measured by using 6 conical flasks each of which containing total $10 \mathrm{ml}$ of Bacillus cereus culture with different volume of crude extract of the antibiotic (starting from $50 \mu \mathrm{l}$ to $400 \mu \mathrm{l}$ ) and incubated for 24 hours at $37^{\circ} \mathrm{C}$ on incubator shaker. The optical densities were measured at $590 \mathrm{~nm}$.

\section{Thin Layer Chromatography}

Thin Layer Chromatography was performed to understand the chemical nature of the Ethyl acetate extracted antimicrobial compound present in the supernatant of isolated Actinomycetes.

Ethyl acetate extracted antibiotic substance was spotted $1.5 \mathrm{~cm}$ from the bottom of silica gel thin-layer chromatography (TLC) plate by using Capillary micropipettes and the solvent allowed evaporating. A glass beaker was poured with $15 \mathrm{ml}$ solvent (mobile phase) containing $100 \%$ Acetone and Methanol $(\mathrm{MeOH})$ in $3: 2$ ratio and a blotting paper was placed into the beaker and it soaked. The beaker was covered with a lid and left for 30 minutes, so that the solvent vapour could saturate the glass container. Then the TLC plate was placed into the beaker and allowed the solvent to travel with the sample which took 55 minutes to reach $2.5 \mathrm{~cm}$ from the top of the TLC plate. The TLC plate was taken out of the beaker and allowed to dry in air for 5-10 minutes. The dried TLC plate was examined under the ultra violet light. Then the plate was stained with lodine by vaporization of lodine in $37^{\circ} \mathrm{C}$ for 60 minutes. 


\section{Results and Discussion \\ Primary Screening of Antimicrobial Compound Producing Actinomycetes from Hospital Dumps Soil}

As actinomycetes have been found to produce many important bioactive compounds of high commercial values, our present study is carried out with aim to screen new bioactive substances from new strains of actinomycetes available in hospital dump soil and drainage soil. Various types of bacterial actinomycetes and fungal colonies were found to be grown on isolation plates. Fifty to sixty colonies were observed per plate. Colonies selected from each plate were 5 to 10 based on colony appearance. Colonies having characteristic features such as powdery appearance with convex, concave or flat surface and color ranging from white, gray to pinkish and yellowish were selected. Colonies found after 1st and 2 nd day of incubation were eliminated because actinomycetes are considered as slow grower. Bacterial configuration same as actinomycetes were accepted from gram staining. Initially 11 isolates of actinomycetes were screened from dump soil and drainage soil of different hospitals in West Bengal, India on the basis of colony morpholology.

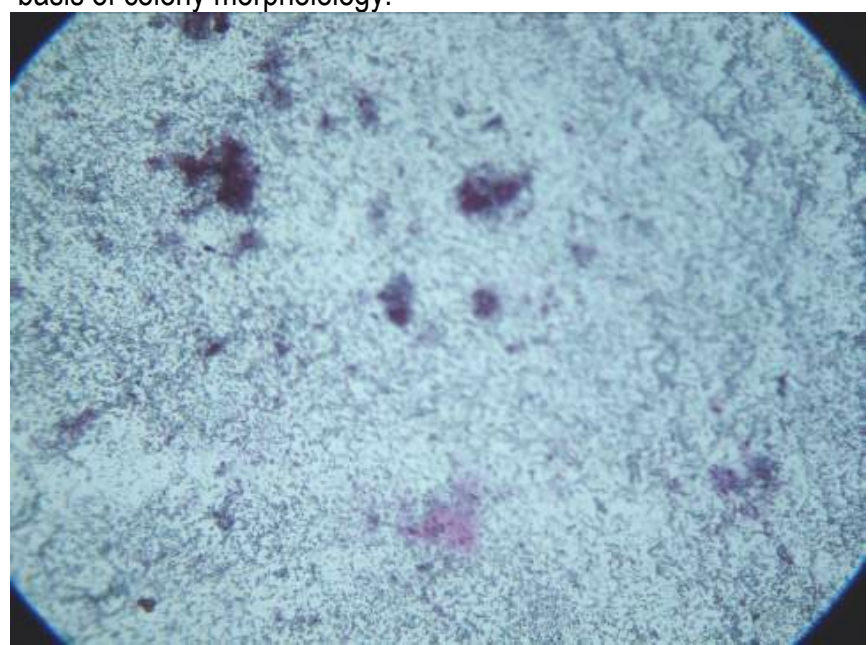

Fig. 1- Microscopic view of isolate after gram staining

All 11 strains of actinomycetes were examined for their antimicrobial activities against $E$. coli and Bacillus cereus by spotting the each of the actinomycetes strain on the plate having the growth of test microorganisms. On the basis of creation of zone of inhibition, only one, out of 11 isolates from primary screening process was found to be an active antibiotic producer (Table no.1).

\section{Table 1- Total no. of tentative isolates from different Hospital} dump soil

\begin{tabular}{|c|c|c|}
\hline Origin & $\begin{array}{l}\text { Total no. of } \\
\text { Isolates }\end{array}$ & $\begin{array}{l}\text { Active Antibiotic } \\
\text { Producers }\end{array}$ \\
\hline $\begin{array}{l}\text { Wasteland soil of Karimpur Rural Hospital, West } \\
\text { Bengal, India }\end{array}$ & 5 & 0 \\
\hline $\begin{array}{l}\text { Drainage soil of Karimpur Rural Hospital West } \\
\text { Bengal, India }\end{array}$ & 2 & 0 \\
\hline $\begin{array}{l}\text { Wasteland soil of Burdwan Medical Collage and } \\
\text { Hospital West Bengal, India }\end{array}$ & 1 & 0 \\
\hline $\begin{array}{l}\text { Drainage soil of Burdwan Medical Collage and } \\
\text { Hospital West Bengal, India }\end{array}$ & 3 & 1 \\
\hline $\begin{array}{l}\text { Drainage soil of Jamshedpur Rural Health centre } \\
\text { West Bengal, India }\end{array}$ & 0 & 0 \\
\hline
\end{tabular}

\section{Morphological and Cultural Characteristics of Selected Isolate}

The antimicrobial compound producing actinomycetes strain was streaked on starch-casein agar media and allowed to grow. Colour, shape and appearance of the strain were examined and strain was also gram stained. Morphological and cultural characteristics of the strain were presented in Table no. 2. The antibiotic producing microorganism was white in colour and found to be gram positive by gram staining.

Table 2- Culture characteristic of isolate on Starch-Casein Agar

\begin{tabular}{|c|c|c|c|c|}
\hline Origin & Colour & Shape & Appearance & $\begin{array}{l}\text { Gram's } \\
\text { reaction }\end{array}$ \\
\hline $\begin{array}{l}\text { rainage soil of Burdwan } \\
\text { edical Collage and } \\
\text { ospital }\end{array}$ & White & Round & $\begin{array}{l}\text { Powdery white discrete } \\
\text { colony with bulging out } \\
\text { from middle. }\end{array}$ & Positive \\
\hline
\end{tabular}

Production of the Antibiotic and Examination of Antibacterial Activity

After the primary selection of the antibiotic producing strain, it was grown in Starch-Casein broth containing necessary ingredients in optimized concentration. Antibiotic was harvested from the culture supernatant by Ethyl acetate extraction method.

Antibacterial activity was studied by Agar diffusion assay by using both crude extract and ethyl acetate extracted part against test gram positive and gram negative microorganisms. Agar diffusion assay with crude antibiotic in supernatant and Ethyl acetate extracted antibiotic showed different degree of zone of inhibition against same set of microorganisms. Ethyl acetate extracted antibiotic was found to be more efficient in killing gram negative microorganisms than its crude counterpart (Effect is almost two fold in terms of the diameter of the zone of inhibition), but it showed very minimal improvements in case of gram positive bacteria as compared to its crude counterpart (Table no. 3). Both antibiotic solutions were found to be more active against Gram-positive than Gram-negative test organisms due to the morphological differences between these microorganisms i.e. a Gram-negative bacterium has an outer polysaccharide membrane carrying the structural lipo-polysaccharide compounds which makes the cell wall impermeable to lipophilic solutes whereas the Gram-positive should be more susceptible having only an outer peptidoglycan layer which is not an effective permeability barrier. Therefore, it can be concluded that the antibiotic produced by the selected actinomycetes strain would be more effective against Gram positive pathogenic microorganisms than the gram negative microorganisms.

Table 3- Antimicrobial activity of isolate (Agar diffusion assay)

\begin{tabular}{|lcc|}
\hline Test microorganisms & Crude & Type of supernatant \\
\hline Bacillus cereus & $3.9 \mathrm{~cm}$ & $4.2 \mathrm{~cm}$ \\
Staphylococcus aureus & $2.9 \mathrm{~cm}$ & $3.2 \mathrm{~cm}$ \\
Escherichia coli & $1.5 \mathrm{~cm}$ & $3.1 \mathrm{~cm}$ \\
Pseudomonas aeroginosa & $1.1 \mathrm{~cm}$ & $2.5 \mathrm{~cm}$ \\
\hline
\end{tabular}

Determination of Minimum Inhibitory Concentration of the Antibiotic

As the antibiotic was found to be more effective against gram positive microorganisms, minimum inhibitory concentration (MIC) was determined against gram positive test microorganism, Bacil- 
lus cereus. The minimum inhibitory concentration was examined by addition of different concentrations of the crude extract of the antibiotic in the culture of Bacillus cereus. The Minimum inhibitory concentration test (MIC) showed gradual decrease in optical density with addition of supernatant in increasing volume; resulting in inhibition of growth of Bacillus cereus. This proved the effectiveness of this antibiotic and approximately $18 \mu \mathrm{g}$ of antibiotic compound was estimated to be inhibitor of growth of $50 \%$ Bacillus cereus (Table 4) (Fig. 2).

Table 4- Antimicrobial activity of isolate (MIC) on Bacillus cereus

\begin{tabular}{lllllll} 
& \multicolumn{5}{c}{ Crude Supernatant } \\
Optical & & $50 \mu \mathrm{l}$ & $70 \mu \mathrm{l}$ & $100 \mu \mathrm{l}$ & $200 \mu \mathrm{l}$ & $400 \mu \mathrm{l}$ \\
Density & Control & $(20 \mu \mathrm{g})$ & $(28 \mu \mathrm{g})$ & $(40 \mu \mathrm{g})$ & $(80 \mu \mathrm{g})$ & $(160 \mu \mathrm{g})$ \\
at 590nm & 1.46 & 0.79 & 0.32 & 0.04 & 0.02 & 0.01 \\
\hline
\end{tabular}

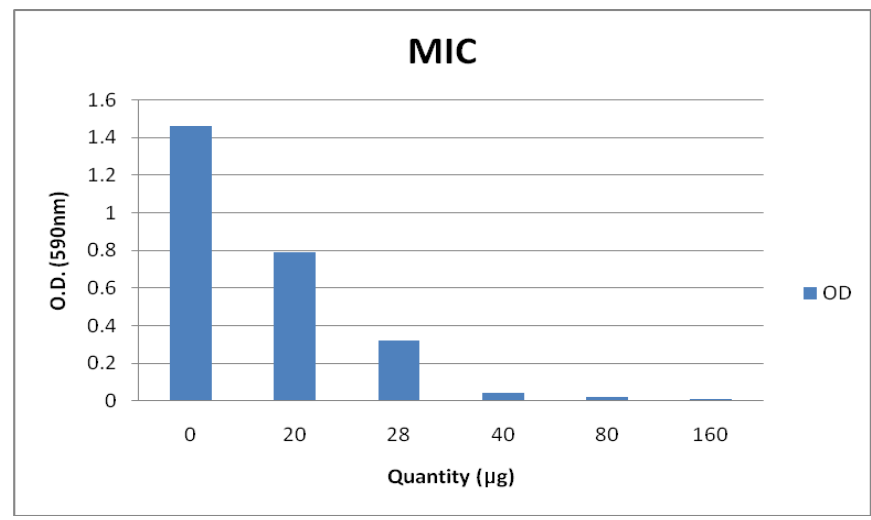

Fig. 2- MIC against Bacillus cereus

\section{Comparison of the Efficacies of the Isolated Antibiotic and Standard Antibiotic}

We have analyzed the efficacy of the isolated antibiotic by determining the comparative profile of antibacterial activities of both standard antibiotic and isolated antibiotic against various microorganism by using equal amount $(100 \mu \mathrm{l}=40 \mu \mathrm{g})$ of both the antibiotics (Table no. 5).

Comparative analysis of antibacterial activities of the isolated antibiotic with the standard antibiotic have clearly shown that isolated antibiotic produced bigger zone of inhibition than the standard antibiotics against all the test microorganisms. Therefore, it can be concluded that, isolated antibiotic is more efficient than the standard antibiotics and it can be useful for medical treatment in future.

Table 5- Comparative study of isolated antibiotic with Standard antibiotic

\begin{tabular}{|lll|} 
Test microorganisms & $\begin{array}{l}\text { Ethyl Acetate } \\
\text { Extracted Antibiotic }\end{array}$ & $\begin{array}{l}\text { Standard Antibiotic } \\
\text { (Chloramphenical } 0.4 \mathrm{mg} / \mathrm{ml} \text { ) }\end{array}$ \\
\hline Bacillus cereus & $4.2 \mathrm{~cm}$ & $3.7 \mathrm{~cm}$ \\
Staphylococcus aureus & $3.2 \mathrm{~cm}$ & $2.8 \mathrm{~cm}$ \\
Escherichia coli & $3.1 \mathrm{~cm}$ & $2.7 \mathrm{~cm}$ \\
Pseudomonas aeroginosa & $2.5 \mathrm{~cm}$ & $2.0 \mathrm{~cm}$ \\
\hline
\end{tabular}

Isolation and Characterization of the Antibiotic by Thin Layer Chromatography

Thin layer chromatography of Ethyl acetate fractionated antibiotic was carried out to assess its chemical nature. TLC analysis of
Ethyl acetate fractionated antibiotics on silica gel plated yielded a single major band under UV light with $R_{f}$ value $(2.44 / 9.2=0.265)$. Elucidation of separated band in TLC plate under ultra violet light assisted to conclude that this antibiotic compound contains a UV absorbing component. But staining of this band with iodine vapour could not show any reliable result. Extraction of this band and antimicrobial assay with this extracted band is under the process.

\section{Conclusion}

The present study led to the conclusion that the antibiotics producing actinomycetes are present in low numbers in wasteland soil and drainage soil of hospitals. But the single actinomycete which has been obtained from hospital wasteland soil showed very high level of antimicrobial activity against pathogenic microorganisms particularly against gram positive pathogenic microorganisms. The isolated microorganism is found to be more potent than the already available standard antibiotics. Therefore, this actinomycete can be exploited to produce good quality and highly effective antibiotic for medical treatment in future.

\section{Acknowledgement}

Authors are thankful to staffs and the Department of Biotechnology, The University of Burdwan for laboratory supports and also to Lovely Professional University.

\section{References}

[1] Oskay M., Tamer A.U. and Azeri C. (2004) African Journal of Biotechnology, 3, 9, 441- 446.

[2] Okami Y. and Hotta K. (1988) Academic Press Inc, New York, 33-67.

[3] Pandey B., Ghimire P. and Agrawal V.P. (2004) International Conference on the Great Himalayas: Climate, Health, Ecology, Management and Conservation, Kathmandu, Organized by Kathmandu University and the Aquatic Ecosystem Health and Management Society, Canada.

[4] Sahin N. and Ugur A. (2003) Turkish Journal of Biology, 27, 79-84.

[5] Levy S.B. (2002) The antibiotic paradox: how misuse of antibiotics destroys their curative powers, 2nd (ed), Perseus Books, Boston.

[6] Livermore D.M. (2003) Clinical Infectious Diseases, 36, 11-23.

[7] Projan S. (2002) Current Opinion in Pharmacology, 2, 513522.

[8] Abbanat D., Macielag M. and Bush K. (2003) Expert Opinion on Investigational Drugs, 12, 379-399.

[9] Barrett C.T. and Barrett J.F. (2003) Current Opinion in Biotechnology, 14, 621-626.

[10]Spizek J. and Tichy P. (1995) Folia Microbiological, 40, 43-50.

[11]Barsby T., Kelly M.T. and Gagne S.M. (2001) Organic Letters 3, 437-440.

[12]Kuster E. (1968) Academic Press, London, pp. 111-124.

[13]Chandrashekhara S. and Basavaraj K. Nanjwade (2010) M.Phil thesis. Vinayaka Missions University, Salem, TN, India.

[14]Bergey's manual of determinative bacteriology (2000) Actinomycetales. $9^{\text {th }}$ edition.

[15]Butler M.S. and Buss A.D. (2005) Biochem Pharmacol., 71, 919-929.

[16]Baltz R.H. (2007) Microbe, 2,125-131. 
[17]Baltz R.H. (2005) SIM News. 55, 186-196.

[18]Bhagabati P., Prakash G. and Vishwanath P.A. (2004) Studies on the antibacterial activity of the Actinomycetes isolated from the Khumbu Region of Nepal. M. Sc. thesis. Tribhuvan University.

[19]Dhanasekaran D., Selvamani S., Panneerselvam A. and Thajuddin N. (2009) Afr. J. Biotechnol.,8: 4159-4162.

[20]Kumar Narendra, Singh Ravi Kant, Mishra S.K., Singh A.K. and Pachouri U.C. (2010) International Journal of Microbiology Research, 2(2), 12-16.

[21]Manjula C., Rajaguru P. and Muthuselvam M. (2009) Advances in Biological Research, 3, (3-4), 84-88.

[22]Newman D.J. and Cragg G.M. (2007) J Nat Prod, 70, 461477.

[23]Syker G. and Skinner F.A. (1973) Academic Press, London \& New York, 1-91 and 231-247.

[24]Williams S.T. and Cross T. (1971) Methods in microbiology, 4, London, 295-334, Academic Press, New York. 